\title{
Impact of electric vehicles on a future renewable energy based power system in Europe with a focus on Germany
}

Diego Luca de Tena ${ }^{1}$, Thomas Pregger*

German Aerospace Center (DLR)

Institute of Engineering Thermodynamics, Stuttgart, Germany

Department of Systems Analysis and Technology Assessment

* Corresponding author. German Aerospace Center (DLR), Institute of Engineering

Thermodynamics, Department of Systems Analysis and Technology Assessment.

Pfaffenwaldring 38-40, D-70569 Stuttgart, Germany. Phone: +49 7116862355.

E-mail address: thomas.pregger@dlr.de

${ }^{1}$ present address: ÅF-Mercados EMI, Madrid, Spain.

E-mail address: diego.luca@afconsult.com

Postprint, submitted to International Journal of Energy Research, Wiley

Only for internal use, please do not cite or circulate this document

How to cite this article: Luca de Tena D, Pregger T. Impact of electric vehicles on a future renewable energy-based power system in Europe with a focus on Germany. Int J Energy Res. 2018;42:2670-2685. https://doi.org/10.1002/ 


\begin{abstract}
Electric mobility is expected to play a key role in the decarbonisation of the energy system. Continued development of battery electric vehicles is fundamental to achieving major reductions in the consumption of fossil fuels and of $\mathrm{CO}_{2}$ emissions in the transport sector. Hydrogen can become an important complementary synthetic fuel providing electric vehicles with longer ranges. However, the environmental benefit of electric vehicles is significant only if their additional electricity consumption is covered by power production from renewable energy sources. Analysing the implications of different scenarios of electric vehicles and renewable power generation considering their spatial and temporal characteristics, we investigate possible effects of electric mobility on the future power system in Germany and Europe. The time horizon of the scenario study is 2050. The approach is based on power system modelling that includes interchange of electricity between European regions, which allows assessing long term structural effects in energy systems with over $80 \%$ of renewable power generation. The study exhibits strong potential of controlled charging and flexible hydrogen production infrastructure to avoid peak demand increases and to reduce the curtailment of renewable power resulting in reduced system operation, generation and network expansion costs. A charging strategy that is optimised from a systems perspective avoids in our scenarios 3.5 to $4.5 \mathrm{GW}$ of the residual peak load in Germany and leads to efficiency gains of $10 \%$ of the electricity demand of plug-in electric vehicles compared to uncontrolled loading.
\end{abstract}

Keywords: electric mobility; electric vehicle; power system; renewable energy; hydrogen production; energy transition 


\section{Abbreviations}

AC

ARTEMIS

$\mathrm{BEV}$

CCGT

CD

CHP

CS

CSP

DLR

DoD

ENTSO-E

EREV

EU

EUR

EV

FCV

GHG

GIS

GT

GW

$\mathrm{H}_{2}$

HVAC
Alternating current

'Assessment and Reliability of Transport Emission Models

and Inventory Systems', research project, European

Commission fifth framework programme

Battery electric vehicle

Combined cycle gas turbine

Charge depleting

Combined heat and power, cogeneration

Charge sustaining

Concentrating solar power

German Aerospace Center

Depth of discharge

European Network of Transmission System Operators

Extended range electric vehicle

European Union

Euro (currency)

Electric vehicle

Fuel cell vehicle

Greenhouse gas

Geographic information system

Gas turbine

Gigawatt

Hydrogen

High voltage alternating current 


\begin{tabular}{|c|c|}
\hline HVDC & High voltage direct current \\
\hline ICT & Information and communication technology \\
\hline $\mathrm{km}$ & Kilometre \\
\hline MEUR & Million Euros \\
\hline $\mathrm{MiD}$ & Mobilität in Deutschland (Germany wide mobility survey) \\
\hline MW & Megawatt \\
\hline NEDC & New European Driving Cycle \\
\hline NREAP & National Renewable Energy Action Plan \\
\hline NTC & Net transfer capacity \\
\hline O\&M & Operation and maintenance \\
\hline PEV & Plug-in electric vehicle \\
\hline Pkm & Passenger-kilometre \\
\hline PTDF & Power transfer distribution factor \\
\hline PV & Photovoltaic \\
\hline REMix & Renewable Energy Mix \\
\hline RES & Renewable energy sources \\
\hline SoC & State of charge \\
\hline Tkm & Tonne-kilometre \\
\hline $\mathrm{TWh} / \mathrm{yr}$ & Terawatt-hour per year \\
\hline V2G & Vehicle to grid (bidirectional) \\
\hline
\end{tabular}




\section{Introduction and Objectives}

Using electricity from renewable energy sources (RES) for transportation is one of the key strategies to reduce Germany's greenhouse gas (GHG) emissions by at least $80 \%$ compared to the year 1990, as described in the German federal government's 'Energy Concept' [1].

Plug-in electric vehicles provide flexibility in battery charging that allows to defer or avoid additional peak demand and can feed electricity back into the grid (vehicle-togrid, V2G) similar to stationary batteries. Both capacities can support the integration of renewable power generation. In addition, an optimized implementation of hydrogen production for fuel cell vehicles via electrolysis and storage systems can have a positive impact on the power system. In this work, these interactions are studied using target-oriented scenarios that assume a massive development of electric vehicles and RES in Europe. These scenarios are in line with about 80\% GHG emission reduction by 2050 (related to 1990). The interaction between the power system and electric vehicles is conditioned by the driving patterns and the availability of wind and solar energy.

For this analysis, we used the energy system model REMix ${ }^{l}$ to answer the following research questions:

- How can we improve the representation of EVs (PEVs and FCVs) in energy system models as flexible consumers considering their real driving patterns?

- What impact can EVs have on the power system in terms of residual peak demand, electricity losses, transmission system expansion and costs

\footnotetext{
${ }^{1}$ Proprietary model of the German Aerospace Center (DLR).
} 
depending on the charging strategy and hydrogen production infrastructure respectively?

The work presented in this paper is derived from a doctoral thesis [2] and a research project [3]. Contrary to most existing studies, the analysis focuses on the period between 2030 and 2050 when electric cars can reach a significant share of the fleet and RES can cover a large share of the electricity demand in Germany and in Europe. Our novel modelling approach comprises a detailed representation of electric vehicles based on real driving patterns and interactions between the power systems of Germany and other European regions.

\section{State of Research}

Numerous models have been developed and applied to find answers to different questions in the field of energy systems or power systems analysis (see e.g. [4] and [5]). Several focus on optimal long-term capacity expansion, whereas others attempt to optimise power plant operation. Energy system models may vary significantly in size and resolution of the area under consideration and can be based on quite different mathematical formulations and algorithms.

The topic of integrating electric vehicles into the power system has already been analysed in a large number of studies and from several research perspectives. Many studies focus on local or regional aspects, e.g. their role in smart grids [6] or in microgrid systems [7], partially with an emphasis on infrastructural requirements. Other studies focus on effects on distribution grids [8], [9], [10] or on possible contributions and benefits of electric vehicle owners for load balancing [11], [12], [13]. Simulations of possible effects and benefits of PEVs ancillary services can be found, for instance, in [14] or [15]. To date, few studies have considered the impacts 
of plug-in electric vehicles on power systems in larger regions. The U.S. scenario analysed by Kintner-Meyer et al. [16] represents a projection of fossil fuel power plant capacity to 2030 and the assumption of $11 \%$ of the light duty vehicle stock representing plug-in hybrid electric vehicles (PHEVs). The authors assumed that RES will not contribute to the daily driving energy of PHEVs because renewable energy plants 'are unlikely to be the marginal resource'. The impact of PEVs on the power system in California was analysed, e.g., by McCarthy [17] for different power system scenarios. Several charging strategies were investigated, such as valley filling, off-peak and daytime charging. However, effects on the integration of variable wind and solar power were not in the focus, and infrastructural needs in the power system in terms of transmission network or storage capacities were not taken into account.

Recent studies by Forrest et al. and Tarroja et al. for California combine vehicle powertrain and charging load dispatch modelling based on real-world vehicle travel patterns with a power system model [18], [19]. Both studies analyse the system effects of controlled charging strategies with regard to storage requirements and the need for dispatchable generation. The approach consists of a stepwise modification of hourly net load profiles as input to the power system modelling. The determination of smart charging strategies was based on bottom-up vehicle and fleet modelling by Zhang et al. [20], which results in different load profiles as an exogenous input to the final power system modelling. The studies confirmed the ability of controlled charging and V2G to significantly reduce storage requirements in power systems with a high share of RES (50\% RES share in 2030 and $80 \%$ in 2050). 
The study of Lund and Kempton [21] considers load balancing for different RES scenarios for Denmark as isolated energy system with up to $100 \%$ wind power. These researchers analysed $\mathrm{V} 2 \mathrm{G}$ impacts on excess electricity production and $\mathrm{CO}_{2}$ emissions assuming $100 \%$ battery electric cars with and without controlled charging and V2G respectively compared to a reference case without any electric vehicles. The study revealed the high potential of intelligent charging and $\mathrm{V} 2 \mathrm{G}$ in supporting the integration of wind power.

Fernandes et al. [22] analysed the impact of EV integration with V2G capability on the Spanish power system operation costs considering various PEV and RES generation shares for the year 2020 and five different types of PEV uses. They integrated PEV representation based on synthetic travel and grid connecting profiles into a two-stage power system dispatch model. The installed capacities of all technologies were exogenously defined for three scenarios with different RES generation and a copper-plate approach without considering possible grid congestion. One main conclusion of this study was that power system operation costs are reduced in particular if a high level of RES generation is combined with high PEV penetration.

Another European case study is presented by Teng et al. [23]. These researchers used an 'advanced stochastic analytical framework' for the analysis of EV effects on carbon emission and calculated RES integration costs for the future UK power system. Charging demand profiles were derived from PEV trials in London, and smart charging was assumed to shift away up to $80 \%$ of PEV demand from peak hours. The analysis of different scenarios for 2030 and 2050 with up to 54\% electricity generation from RES confirmed significant carbon emission and RES system integration costs benefits, especially for the 2050 scenario with high RES 
integration and if PEVs are able to provide frequency response in addition to smart balancing. Possible grid congestion effects within UK were not considered in this study.

Few studies also exist with a focus on the German energy transition. Dallinger et al. [24] compared the system effects of PEV integration in California and Germany for a scenario up to 2030. The analysis was based on an agent-based simulation model that includes real-time prices as control signals and a detailed simulation of individual driving behaviour. Because of high battery degradation costs, they focused on PEV load shifting potential without V2G. They demonstrated benefits regarding the integration of RES into the power generation due to load balancing effects in both countries with higher effects in California due to different RES characteristics.

In contrast to simplified statistical distributions that are often used to reproduce synthetic driving profiles, Metz and Doetsch [25] used real-world driving profiles that were obtained from the German mobility panel [26]. However, the interaction with the power supply system was simulated there based on simplified charging profiles, one using a static shift by time signals and a second using a dynamic shift by price signals.

Power system impacts of PEVs in Germany were also analysed by Schill and Gerbaulet [27] for different scenarios of 2020 and 2030. These researchers used a numerical optimization model formulated as mixed integer linear program. The model simultaneously calculates power plant dispatch and PEV charging taking into account generation constraints for thermal plants including cogeneration plants. They assumed an uncongested transmission network and abstracted from possible power exchanges with neighbouring countries. Their results show that a 'cost-driven' (controlled) charging mode compared to a 'user-driven' (uncontrolled) charging 
mode leads on the one hand to a significant reduction of RES curtailment but on the other hand to an increase of power generation from rather inflexible lignite power stations in substitution for more expensive generation from gas-fired plants.

EV effects on national and European scale were modelled by Verzijlbergh et al. [28] by representing PEV mobility based on current driving patterns within an EU power unit commitment dispatch model. They calculated the hourly dispatch of exogenously defined future generation and transmission capacities with a weekly rolling horizon approach for different scenario years. The model setup considers 32 regions in Europe and a maximum overall RES share of $50 \%$ of annual power generation with considerable higher shares in some regions according to an ENTSOE scenario [29]. The results show that both the controlled PEV charging and the power exchange between regions reduce dispatch costs and RES curtailment. Increasing volumes of RES lead to an increasing complementary role of both options for load balancing.

\section{Motivation}

The literature survey reveals that several studies already demonstrated the possible benefits of controlled charging for the integration of RES at regional and national scale. However, all modelling approaches still have much room for improvement either with regard to scope, further case scenarios and use of realistic profiles or the model structure, its parametrisation and coverage of technologies. In contrast to previous work, this contribution aims to analyse systemic effects of electric mobility on the integration of renewable power generation under the assumptions of a widespread use of electric cars and a high share of renewable power of more than $80 \%$. In addition to battery electric vehicles, the analysis considers the complementary development of hydrogen fuelled electric vehicles. 
The analysis was carried out using an energy system model that allows representing the spatial and temporal characteristics of renewable power generation and also considers real-world vehicle travel patterns using a novel approach. In contrast to most approaches, REMix models electricity generation from wind and solar energy based on real weather data and can consider the complex interactions between hourly demand, variable and dispatchable power generation, storage, and high-voltage power transmission between regions [30]. Interactions between the power, the transport and the heating sectors are taken into account by integrating corresponding demand profiles and technology options. The model is able to analyse cost optimized dispatch and infrastructural needs in the future energy system taking into account different alternative storage and load shifting options. Compared to previous studies, possible power transfers between Germany and neighbouring countries and grid constraints within Germany are taken into account by the spatial resolution of the model. It can thus also evaluate to which extent electric vehicles in regions with high population density but small renewable energy resources can integrate renewable power from regions with large resources and how much investment in transmission capacity this would require.

\section{Methodology and Main Assumptions of the Analysis}

\subsection{Model development focussing on EV integration}

REMix couples the well-established approach of linear optimisation with georeferenced data on power demand and renewable power generation potentials [31]. The model assumes exogenously specified power generation scenarios and determines additional back-up generation capacity, storage use and the transmission network expansion required to supply the demand at the least cost. It also determines 
the optimal loading strategy for plug-in electric vehicles and the least cost hydrogen generation for $\mathrm{H}_{2}$ stations including their contribution to RES integration.

Figure 1 illustrates on the left side the basic approach for representing EVs in REMix. This figure also illustrates how the additional power demand of EVs and flexibility in battery charging and hydrogen generation are integrated into the optimization model as additional technology options.

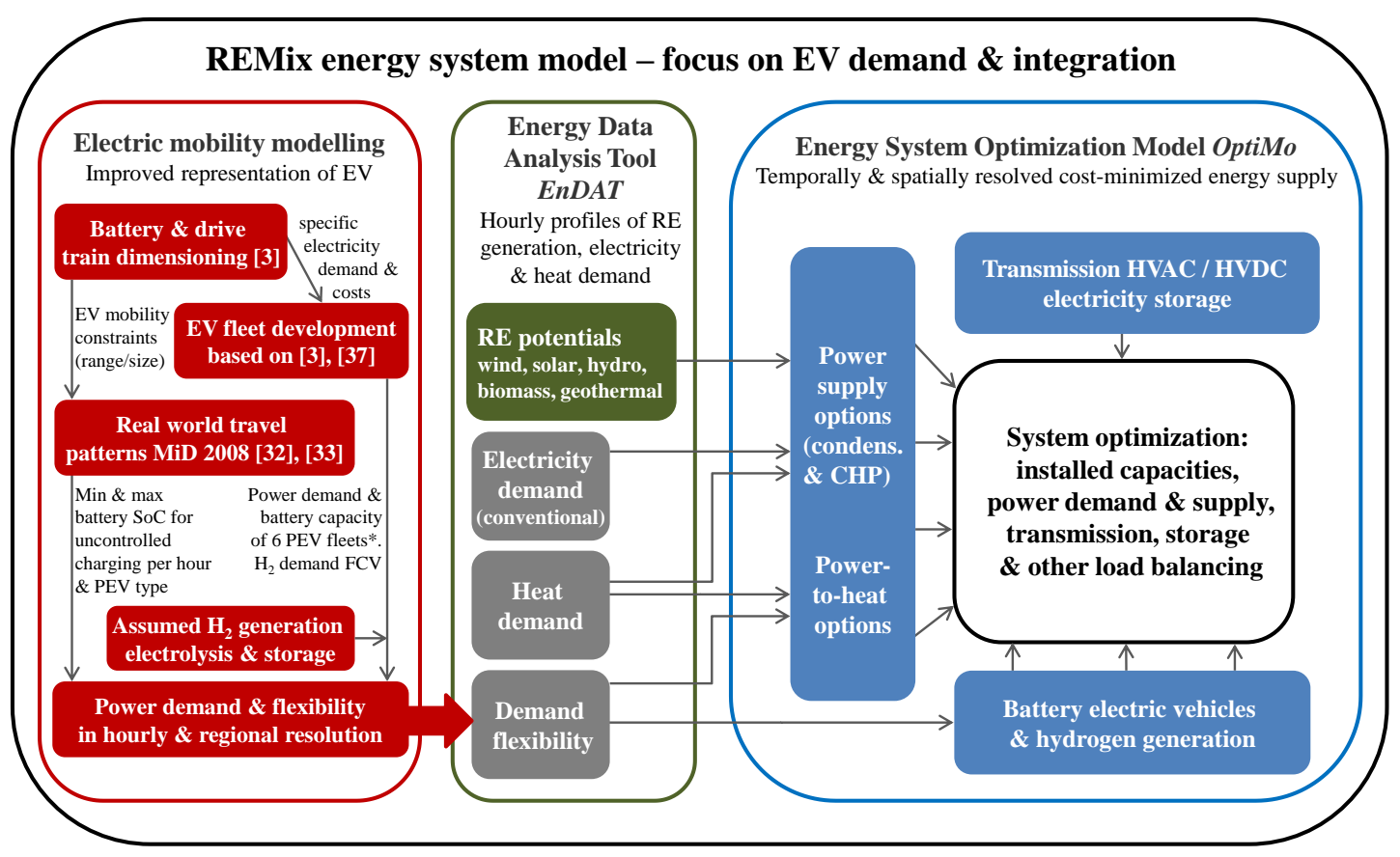

Figure 1: REMix model structure including new approach for EV representation (left)

* BEV \& EREV: small, medium and large vehicles

The potentials of RES were estimated based on geo-referenced satellite data and weather service data from the year 2006, representing average solar and wind conditions. The approach provides potentials and feed-in time series for renewable electricity with spatial $(10 \mathrm{~km} \times 10 \mathrm{~km}$ resp. regions) and temporal (hourly) resolutions.

The new approach to modelling flexibility of PEV battery charging was derived from Propfe and Luca de Tena [32] and is based on real-world vehicle travel data [33]. 
From the 17,000 daily driving profiles available only those were considered that are suitable for PEVs depending on their range. For each of the resulting suitable driving profiles, the maximum and minimum possible battery state-of-charge (SoC) profiles were derived. These SoC profiles also depend on battery dimensioning and other vehicle characteristics that influence the specific electricity demand per kilometre driven. Finally, to calculate the maximum and minimum battery SoC profile of the entire vehicle fleet confidence intervals were applied to the maximum and minimum individual profiles. The difference between these curves represents the load balancing potential of the PEV fleet for each hour. Figure 2 illustrates an example of the resulting maximum and minimum SoC profiles for BEVs. For a confidence coefficient of $95 \%$, i.e., within the area comprised by the solid blue and red lines, 95\% of all driving profiles would still be feasible with the defined EV layout regarding battery capacity and drive train.

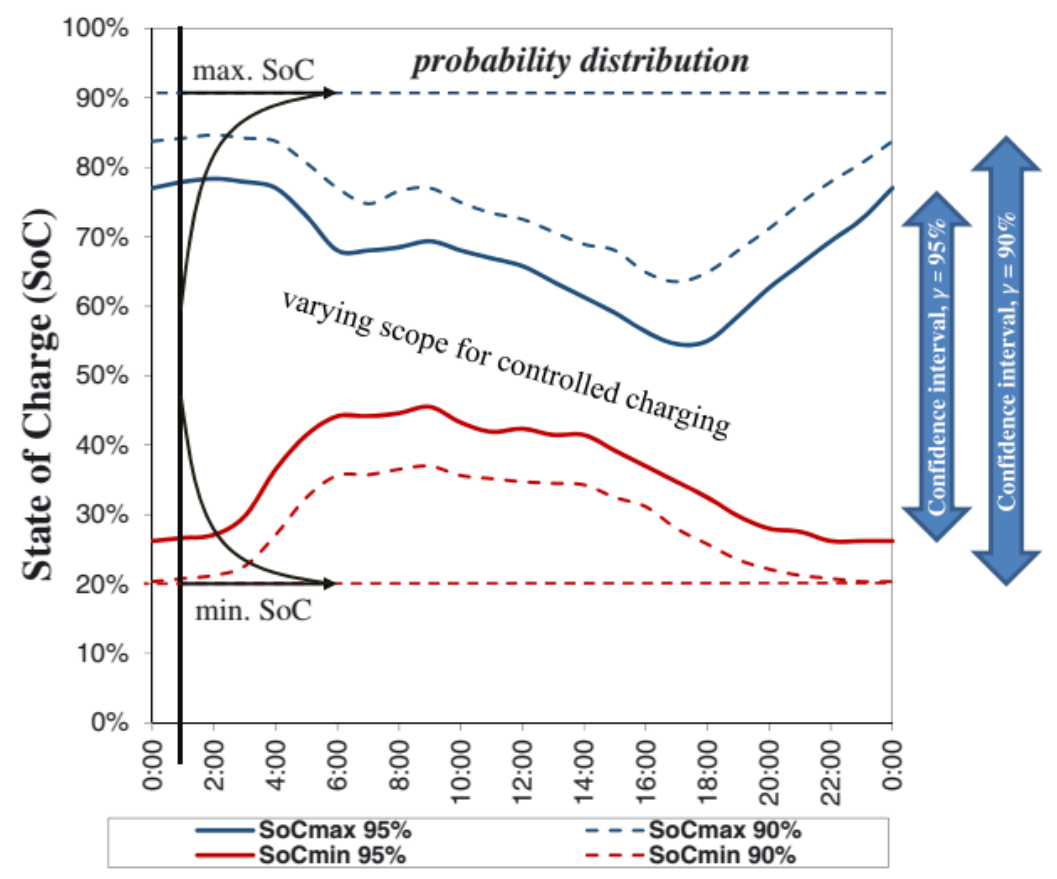

Figure 2: Method for the calculation of the hourly flexibility potential of the PEV fleet based on maximum and minimum possible state-of-charge (SoC) profiles according to [32]. 
The existing AC network was represented with zonal Power Transfer Distribution Factors (PTDF) and Net Transfer Capacities (NTC). This simplified approach assumes a linear relation between feed-in and power flows. Transmission bottlenecks within each region considered and reactive power flows are neglected. The network data used were calculated in the framework of [3] based on a load flow model using publicly available transmission network information. In addition, the model allows evaluating the economic convenience from systems perspective of installing additional HVDC lines to create an HVDC supergrid. Electricity losses and infrastructure needs in distribution grids were not considered in the modelling approach. Computing time was reduced by solving the optimisation problem applying a two-stage approach. First, the least cost expansion of power transfer capacities between regions, of electricity storages and of gas turbines in Europe was calculated with a temporal resolution of 5 hours. Sensitivity tests in hourly resolution showed that this approach - which leads to 1,752 load blocks per year - results in differences on the supply side that do not substantially affect the outcome of the expansion planning for Germany. The calculation also provided the interchanges between Germany and its neighbouring countries as an input for the second modelling step in hourly resolution. The second calculation determined the cost minimized operation of the German power system by considering grid transfer capacities between seven defined regions within Germany and the power exchange with neighbouring regions.

REMix considers different thermal power plant technologies and calculates the hourly dispatch based on variable operating costs following a merit order. Main variable cost components are fuel costs, the costs of carbon emission allowances and operation and maintenance. The dispatch of thermal units is also dependent on the 
start-up costs, which are determined by additional wear and tear and by the fuel consumption during start-ups. Finally, electricity storage technologies, such as pumped storage, and combined heat and power (CHP) plants are represented. The model allows a flexible operation of CHP plants with heat storage capacities and electric heaters that allow decoupling power generation from heat demand. Hence, wind and solar power can also be used in the heating sector in times of high RES generation and low demand. Hydrogen fuelling stations for FCVs comprise on-site electrolysis and a local storage capacity. More information about the model development and all data assumptions for representing technological options are provided by Luca de Tena [2]. 


\subsection{Modelling assumptions}

\section{Future vehicle concepts}

The analysis considers the integration of three different types of electric vehicles, battery electric vehicles (BEVs), extended range electric vehicles (EREVs) and fuel cell vehicles (FCVs). BEVs and EREVs were characterised according to [3] as shown in Table 1 and Table 2.

Table 1: Assumed technical specifications for BEVs based on [3].

\begin{tabular}{lccccccc}
\hline & \multicolumn{4}{c}{ Small } & \multicolumn{2}{c}{ Medium } & \multicolumn{2}{c}{ Large } \\
\hline & Unit & $\mathbf{2 0 1 0}$ & $\mathbf{2 0 5 0}$ & $\mathbf{2 0 1 0}$ & $\mathbf{2 0 5 0}$ & $\mathbf{2 0 1 0}$ & $\mathbf{2 0 5 0}$ \\
Max. speed & $\mathrm{km} / \mathrm{h}$ & \multicolumn{2}{c}{120} & \multicolumn{2}{c}{140} & \multicolumn{2}{c}{160} \\
$\begin{array}{l}\text { Acceleration } \\
(0-100 \mathrm{~km} / \mathrm{h})\end{array}$ & $\mathrm{s}$ & \multicolumn{2}{c}{18} & \multicolumn{2}{c}{14} & & \multicolumn{2}{c}{12} & \\
Vehicle weight & $\mathrm{kg}$ & 1155 & 806 & 1521 & 1028 & 1964 & 1303 \\
$\begin{array}{l}\text { Battery capacity } \\
(10-95 \% \text { usable })\end{array}$ & $\mathrm{kWh}$ & 14 & 14 & 22.5 & 22 & 33 & 31 \\
$\begin{array}{l}\text { Consumption } \\
\text { NEDC / ARTEMIS * }\end{array}$ & $\mathrm{kWh} /$ & $10 / 14.8$ & $7 / 10.5$ & $12 / 19$ & $8 / 12.9$ & $14 / 25.3$ & $9 / 16.8$ \\
$\begin{array}{l}\text { Auxiliary } \\
\text { consumption ** }\end{array}$ & $\mathrm{kW}$ & 1.0 & 0.75 & 1.5 & 1.1 & 2.0 & 1.5 \\
$\begin{array}{l}\text { Electric range } \\
\text { NEDC / ARTEMIS }\end{array}$ & $\mathrm{km}$ & $120 / 80$ & $180 / 113$ & $160 / 101$ & $240 / 145$ & $200 / 111$ & $300 / 157$ \\
\hline
\end{tabular}

* ARTEMIS driving cycles: $26 \%$ of kilometres driven on highways, $45 \%$ extra urban and $29 \%$ urban.

** Heating, air conditioning, others. 
Table 2: Assumed technical specifications for EREVs based on [3].

\begin{tabular}{|c|c|c|c|c|c|c|c|}
\hline & & \multicolumn{2}{|c|}{ Small } & \multicolumn{2}{|c|}{ Medium } & \multicolumn{2}{|c|}{ Large } \\
\hline & Unit & 2010 & 2050 & 2010 & 2050 & 2010 & 2050 \\
\hline Max. speed (CD) & $\mathrm{km} / \mathrm{h}$ & \multicolumn{2}{|c|}{120} & \multicolumn{2}{|c|}{140} & \multicolumn{2}{|c|}{160} \\
\hline Max. speed (CS) & $\mathrm{km} / \mathrm{h}$ & \multicolumn{2}{|c|}{110} & \multicolumn{2}{|c|}{130} & \multicolumn{2}{|c|}{150} \\
\hline $\begin{array}{l}\text { Acceleration } \\
(0-100 \mathrm{~km} / \mathrm{h})\end{array}$ & $\mathrm{s}$ & \multicolumn{2}{|c|}{18} & \multicolumn{2}{|c|}{14} & \multicolumn{2}{|c|}{12} \\
\hline Vehicle weight & $\mathrm{kg}$ & 1241 & 878 & 1574 & 1121 & 1966 & 1406 \\
\hline $\begin{array}{l}\text { Battery capacity } \\
\text { (35-90\% usable) }\end{array}$ & $\mathrm{kWh}$ & 13 & 13 & 16 & 16 & 18 & 17 \\
\hline $\begin{array}{l}\text { Consumption (CD) } \\
\text { NEDC / ARTEMIS * }\end{array}$ & $\begin{array}{l}\mathrm{kWh} / \\
100 \mathrm{~km}\end{array}$ & $10 / 14.8$ & $7 / 10.5$ & $12 / 17.9$ & $8 / 12.2$ & $14 / 23.7$ & $9 / 15.8$ \\
\hline $\begin{array}{l}\text { Consumption (CS) } \\
\text { NEDC / ARTEMIS }\end{array}$ & $1 / 100 \mathrm{~km}$ & $4 / 5.9$ & $2 / 3.0$ & $4.5 / 6.7$ & $2.5 / 3.8$ & $5 / 8.5$ & $3 / 5.3$ \\
\hline $\begin{array}{l}\text { Auxiliary } \\
\text { consumption } * *\end{array}$ & $\mathrm{~kW}$ & 1.0 & 0.75 & 1.5 & 1.1 & 2.0 & 1.5 \\
\hline $\begin{array}{l}\text { Electric range } \\
\text { NEDC / ARTEMIS }\end{array}$ & $\mathrm{km}$ & $70 / 48$ & $100 / 68$ & $70 / 49$ & $100 / 72$ & $70 / 42$ & $100 / 59$ \\
\hline
\end{tabular}

* ARTEMIS driving cycles: $26 \%$ of kilometres driven on highways, $45 \%$ extra urban and $29 \%$ urban.

** Heating, air conditioning, others.

We assumed that EREVs run in charge-depleting (CD) mode until the minimum SoC is reached. Thereafter, the vehicle is driven in charge-sustaining (CS) mode while the auxiliary power unit (range extender) is operating. Costs of the battery packs were assumed to decrease from approximately 400 EUR to 200 EUR per kWh of storage capacity in 2050 (reflecting development goals of the U.S. Advanced Battery Consortium of 2010 [34]), and energy density was increased from $80 \mathrm{Wh} / \mathrm{kg}$ to around $350 \mathrm{Wh} / \mathrm{kg}$ on the battery pack level. Because battery costs have fallen considerably over the last years our cost development path became a rather conservative assumption, however, still lower than today's battery costs. 
The specific energy demand was estimated for each vehicle type based on dynamic simulations ${ }^{2}$. The driving cycles used are NEDC, which typically underestimate the real energy demand of vehicles, and more appropriate cycles derived from the ARTEMIS research project (see [35]). The consumption data used for vehicle fleet simulation consider auxiliary systems such as air conditioning and heating. In addition, specific hydrogen consumption of FCVs in 2050 was defined to be around 0.7 MJ/Pkm for passenger transportation and 1.2 MJ/Tkm for freight transportation [36].

\section{Future passenger vehicle fleet}

The scenario of the German passenger car fleet [3] was developed with the tool VECTOR $21^{3}$, which simulates the competition of vehicle technologies in the car market [37]. The optimistic scenario for Germany results in around 5 million PEVs in 2030 and 27 million in 2050 (thereof around 11 million BEVs), under the assumption, that the German energy transition can be achieved (see also [38]). The scenario presumes an optimistic development of new battery technologies and stricter $\mathrm{CO}_{2}$ emissions standards in the future. We assumed hydrogen use to be a complementary option for larger vehicles in future transportation to meet the overall decarbonisation target. FCVs already achieved a high stage of development and still promise considerably higher ranges than BEVs. For Europe as a whole, we assumed

2 DLR Institute of Vehicle Concepts, Stuttgart, Germany; simulations with Modelica library Alternative Vehicles [3]

3 DLR Institute of Vehicle Concepts, Stuttgart, Germany; simulations with VECTOR21 model (Vehicle Technology Scenario Model) in the framework of [3]. See also recent work in the frame of http://www.project-emap.eu/deliverables.htm, especially 'D2.1 Analytic Framework: Parameters, Data \& Methodology' and reports on scenario results and evaluation. 
similar fleet developments as in Germany taking into account country-specific population forecasts and data on vehicle ownership.

\section{Future PEV charging}

We assumed that in the introduction phase, charging equipment is installed above all in private areas, i.e. in households and in the workplace. Public charging e.g. in parking lots, shopping malls, at train stations, and universities would become important at a later stage. The following probabilities of grid connection were assumed depending on the trip purpose (based on [32]): $70 \%$ at home, $50 \%$ at work, $40 \%$ for education, $30 \%$ for shopping and leisure, and $10 \%$ for escort, business, private and other purposes.

The average connection power was assumed to develop from $3.7 \mathrm{~kW}$ today (singlephase $230 \mathrm{~V}, 16 \mathrm{~A})$ to $5.5 \mathrm{~kW}$ in 2030 and $8.5 \mathrm{~kW}$ in 2050. Charging and discharging efficiencies were set to $95 \%$ for both directions. The costs of additional battery degradation owing to $\mathrm{V} 2 \mathrm{G}$ were considered depending on the daily depth of discharge (DoD) and interpolated between $1 € \mathrm{ct} / \mathrm{kWh}$ power feed-in if the battery is almost full and $8.5 € \mathrm{ct} / \mathrm{kWh}$ if the battery is almost discharged. A similar approach as used by Link et al. [39] was applied to model battery degradation for different DoDs taking into account the battery development targets of the U.S. Advanced Battery Consortium of 2010 [34]).

\section{Future power system}

The power generation scenarios for Germany were derived from [36] (see also [40]). They take into account targets for RES expansion as described in the German federal government's 'Energy Concept' [1] and the phase-out of nuclear power in accordance with the Bundestag decision of 30 June $2011\left(13^{\text {th }}\right.$ Amendment of the 
Atomic Energy Act). The penetration of RES accounts for around 65\% of electricity generation in Germany by 2030 and $87 \%$ by 2050. Similar RES penetrations were assumed for the considered European regions. The scenario was based on [41], taking into account recent European trends and targets with regard to demand and supply structures (e.g. NREAP). The resulting power demand without EVs is approximately $490 \mathrm{TWh} / \mathrm{yr}$ in Germany in 2050 - assuming a demand reduction of approximately $15 \%$ between today and 2050 - and $3040 \mathrm{TWh} / \mathrm{yr}$ in all European regions considered (incl. Germany). The assumed additional power demand of EVs in 2050 is $134 \mathrm{TWh} / \mathrm{yr}$ (thereof $49 \mathrm{TWh} / \mathrm{yr}$ for PEVs) in Germany and $677 \mathrm{TWh} / \mathrm{yr}$ in all regions (see Figure 3).
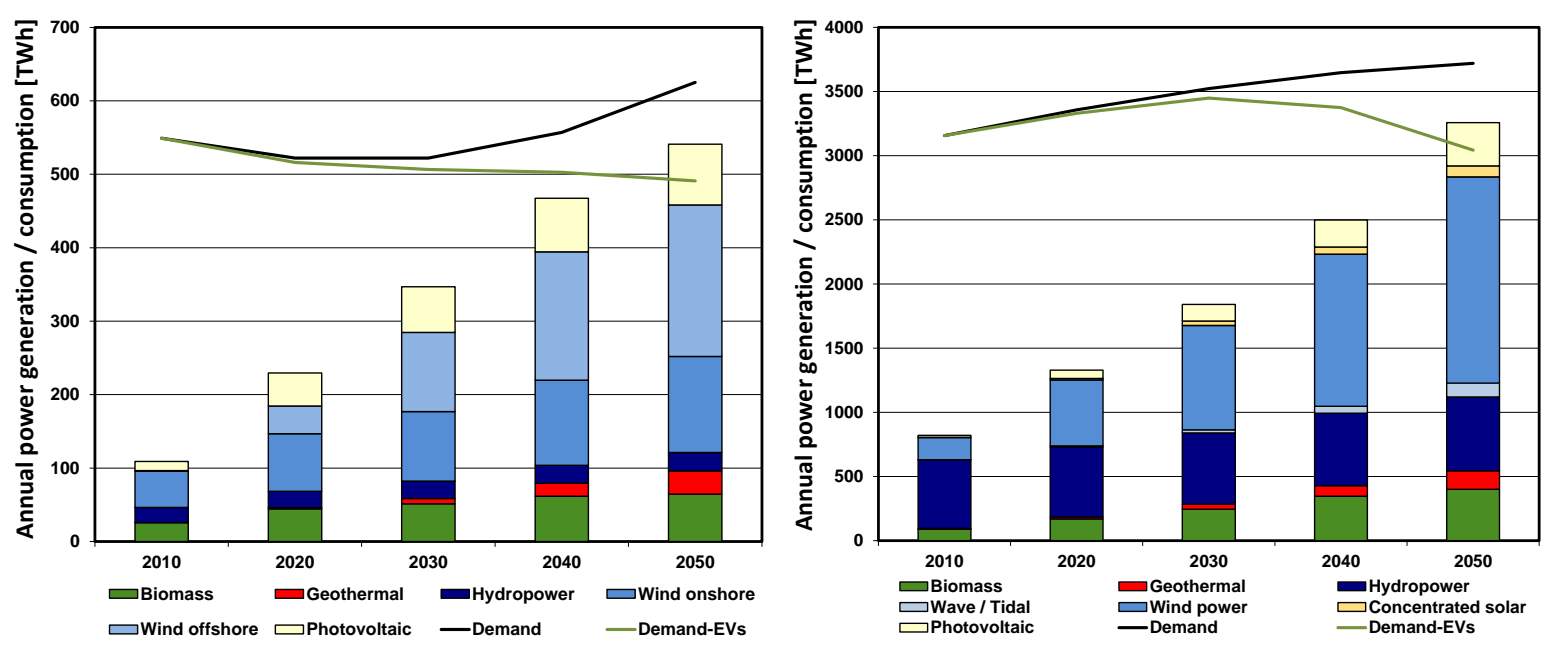

Figure 3: Assumed scenario of RES power generation and electricity demand (total and minus EVs) in Germany (left) and all considered regions (right) - Base scenario with local supply.

The impact of EVs on the power system is studied by comparing different scenarios of EV integration and power generation. The scenario Base (see Section 3.3) assumes that the annual renewable electricity used in Germany is domestically generated. Because the potentials of biomass, hydro and geothermal power generation are limited, the scenario Base contains a large share of power generation 
from wind and photovoltaics. Thus, this scenario requires a rather high power system flexibility to avoid excess power and supply gaps. A Trans-European electricity supply including RES potentials in North Africa was therefore considered in a second scenario called Trans, where interchanges and dispatchable imports of solar thermal power (CSP) play an important role. In Trans, approximately $130 \mathrm{TWh} / \mathrm{yr}$ of electricity is imported in Germany in 2050 and $590 \mathrm{TWh} / \mathrm{yr}$ in all regions considered, which significantly reduces the share of variable RES. A third scenario $N E V$ (no electric vehicles) assumes that PEVs and FCVs will not be widely used in the long term. Renewable power generation is reduced in this scenario to account for the lower power demand. The resulting installed capacities of power generation in Germany (exogenously assumed) are presented in Table 3.

Table 3: Assumed power generation capacities for Germany in 2030 and 2050.

\begin{tabular}{lrrrrrr}
\hline in GW & \multicolumn{2}{c}{ Base Scenario } & \multicolumn{2}{c}{ Trans Scenario } & \multicolumn{2}{c}{ NEV Scenario } \\
& $\mathbf{2 0 3 0}$ & $\mathbf{2 0 5 0}$ & $\mathbf{2 0 3 0}$ & $\mathbf{2 0 5 0}$ & $\mathbf{2 0 3 0}$ & $\mathbf{2 0 5 0}$ \\
\hline Photovoltaic & 70 & 88 & 61 & 64 & 57 & 64 \\
Wind onshore & 41 & 50 & 36 & 37 & 34 & 36 \\
Wind offshore & 28 & 52 & 25 & 38 & 23 & 37 \\
Biomass \& biogas CHP & 9.5 & 12.0 & 9.0 & 10.8 & 9.0 & 10.8 \\
Hydro & 4.9 & 5.2 & 4.9 & 5.2 & 4.9 & 5.2 \\
Geothermal & 1.1 & 4.9 & 1.0 & 3.6 & 0.9 & 3.5 \\
Import RES & 0 & 0 & 6.4 & 19.1 & 0 & 0 \\
Lignite \& waste (incl. CHP) & 13.2 & 2.7 & 13.2 & 2.7 & 13.2 & 2.7 \\
Hard coal (incl. CHP) & 14.4 & 6.8 & 14.4 & 6.8 & 14.4 & 6.8 \\
CCGT (incl. large CHP) & 19.4 & 22.3 & 19.4 & 22.3 & 19.4 & 22.3 \\
Gas turbines & 1.8 & 1.9 & 1.8 & 1.9 & 1.8 & 1.9 \\
Small gas fired CHP & 6.0 & 6.5 & 6.0 & 6.5 & 6.0 & 6.5 \\
Total & $\mathbf{2 1 0}$ & $\mathbf{2 5 2}$ & $\mathbf{1 9 8}$ & $\mathbf{2 1 8}$ & $\mathbf{1 8 4}$ & $\mathbf{1 9 7}$ \\
$\quad$ thereof CHP & 35 & 34 & 35 & 34 & 35 & 34 \\
Pumped storage & 8.1 & 8.1 & 8.1 & 8.1 & 8.1 & 8.1 \\
\hline
\end{tabular}

Approximately $35 \mathrm{GW}$ of CHP plants with heat storage capability and electric heater allow the decoupling of power generation from heat demand and the use of excess generation in the heating sector.

The analysis focuses on Germany; however, it takes into account power interchanges with other European countries and North Africa having different load profiles and 
renewable resources. Figure 4 shows the regions under consideration, seven of them within Germany to account for power flows through the country and ten to represent the power flows between regions. We exogenously assumed installed transmission capacities according to the network development plan by ENTSO-E [42] for the year 2010 as the starting grid. Installed wind power capacities in all regions reach 280 GW in the Base scenario in 2050. The PV, hydro, wave/tidal, and geothermal power capacities are approximately $150 \mathrm{GW}, 174 \mathrm{GW}, 14 \mathrm{GW}$ and $16 \mathrm{GW}$, respectively. Remaining fossil capacities account for $32 \mathrm{GW}$ coal, $7 \mathrm{GW}$ lignite and waste, 126 GW gas power plants and $80 \mathrm{GW}$ gas turbines. Power generation capacities for biomasses and solar thermal plants (CSP) account for $104 \mathrm{GW}$ and for $7.5 \mathrm{GW}$, respectively.

Endogenous expansions of gas turbines for back-up generation and power transmission capacities (HVDC lines) are essential parameters in this study. Therefore, assumptions about their costs are important factors (see Table 4). Because cost assumptions for future HVDC lines are very uncertain different scenario variants were assumed for the analyses (see Section 4.3). A complete documentation of assumptions can be found in [2].

Table 4: Specific costs and properties assumed for HVDC links and gas turbines (GT).

\begin{tabular}{llrrrr}
\hline Investment costs $\left(\boldsymbol{€}_{\mathbf{2 0 0 9}}\right)$ & unit & $\mathbf{2 0 1 0}$ & $\mathbf{2 0 3 0}$ & $\mathbf{2 0 5 0}$ & electricity losses \\
\hline Overhead line $3.2 \mathrm{GW}, 600 \mathrm{kV}$ & $€ / \mathrm{MW} \cdot \mathrm{km}$ & 140 & 130 & 120 & $4.5 \% / 1000 \mathrm{~km}$ \\
Sea cable $3.2 \mathrm{GW}, 600 \mathrm{kV}$ & $€ / \mathrm{MW} \cdot \mathrm{km}$ & 975 & 900 & 825 & $2.7 \% / 1000 \mathrm{~km}$ \\
Underground cable $2.2 \mathrm{GW}, 600 \mathrm{kV}$ & $€ / \mathrm{MW} \cdot \mathrm{km}$ & 489 & 451 & 415 & $2.7 \% / 1000 \mathrm{~km}$ \\
Each converter station & $€ / \mathrm{MW}$ & 120 & 102 & 90 & $0.7 \% /$ conversion \\
Gas turbine $(\mathrm{GT})$ & $€ / \mathrm{kW}$ & 400 & 400 & 400 & $1 \%$ own consumption \\
\hline
\end{tabular}

* further assumptions: interest rate 6\%, amortisation time HVDC infrastructure 40 years, fixed O\&M HVDC 1\%/yr, amortisation time GT 25 years, fixed O\&M GT 2\%/yr, net efficiency GT 45.5\% in 2030, 46.5\% in 2050 


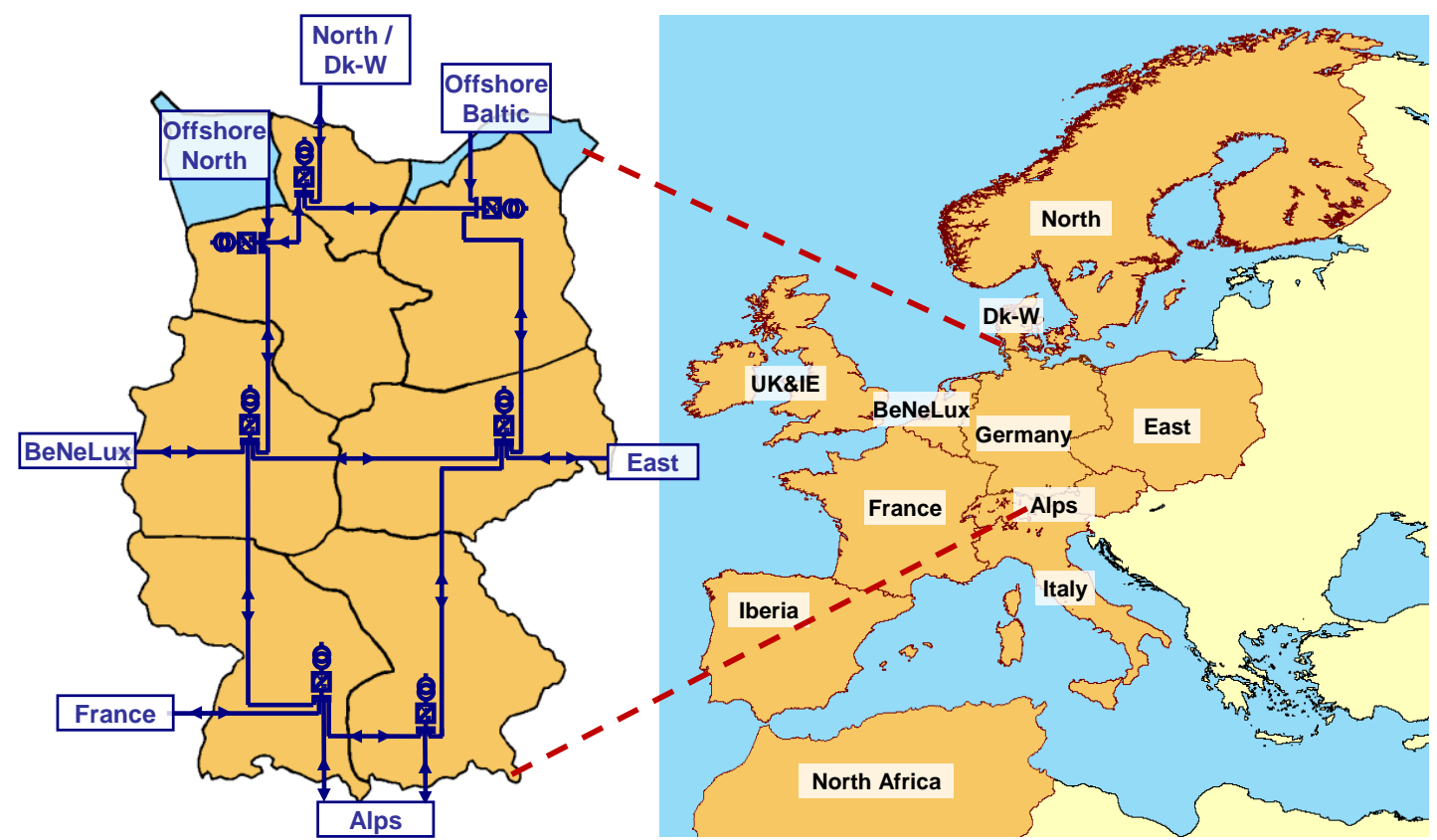

Figure 4: Delimitation of regions for the REMix modelling of power transmission (existing AC and future DC lines).

\section{Hydrogen generation}

Table 5 summarises the main parameters assumed for on-site hydrogen production at fuelling stations. We assumed that hydrogen is locally stored at 350 bar with a storage capacity equal to 12 hours of the average hydrogen demand. Average utilisation was set to 4,000 full load hours per year for predefining the connection power of the electrolysers. This makes it possible to compensate the load variations between day and night, as well as guarantees hydrogen supply on days with a demand that doubles the average value.

Table 5: Characteristics of the considered reference hydrogen fuelling station.

\begin{tabular}{llllll}
\hline & $\mathbf{2 0 1 0}$ & $\mathbf{2 0 2 0}$ & $\mathbf{2 0 3 0}$ & $\mathbf{2 0 4 0}$ & $\mathbf{2 0 5 0}$ \\
\hline $\begin{array}{l}\text { Efficiency electrolysis } \\
\text { (incl. periphery) }\end{array}$ & $57.6 \%$ & $60.5 \%$ & $63.7 \%$ & $67.3 \%$ & $71.3 \%$ \\
$\begin{array}{l}\text { Efficiency electrolysis } \\
\text { \& compression to 800 bar }\end{array}$ & $54.8 \%$ & $57.4 \%$ & $60.3 \%$ & $63.5 \%$ & $67.0 \%$ \\
$\begin{array}{l}\text { Utilisation electrolyser } \\
\text { Hydrogen storage capacity }\end{array}$ & \multicolumn{3}{c}{$\begin{array}{l}\text { around 4,000 full load hours } \\
\text { 12 hours of average demand }\end{array}$} \\
\hline
\end{tabular}


The hydrogen consumption scenario for Germany is equivalent to scenario B of [36], which assumes a hydrogen use of $0.4 \mathrm{TWh} / \mathrm{yr}$ in 2030, $15.1 \mathrm{TWh} / \mathrm{yr}$ in 2040 and 56.9 $\mathrm{TWh} / \mathrm{yr}$ in 2050. The installed electrolyser capacity reaches $170 \mathrm{MW}$ in 2030 and 21.2 GW in 2050. This demand scenario was scaled for the other modelled regions based on road freight transport statistics [43]. Considering total hydrogen demand of all European regions (incl. Germany) results in around 2 TWh/yr in 2030 and 290 $\mathrm{TWh} / \mathrm{yr}$ in 2050.

\subsection{Scenario definitions}

The following scenarios and scenario variants were used to analyse EV integration. They represent significantly different development paths of the power system and frame conditions for EV integration considering main targets of the energy transition.

\section{Base case (Base)}

The Base scenario represents an optimistic path towards a high share of variable local renewable power (65\% RES share in 2030 and $87 \%$ in 2050) and a grid expansion with HVDC underground cables having a specific capacity of $2.2 \mathrm{GW}$ per transmission line. $66 \%$ of passenger cars in Germany in 2050 are assumed to be PEVs consuming around $49 \mathrm{TWh} / \mathrm{yr}$ of electricity. In addition, the German transport sector consumes around $85 \mathrm{TWh} / \mathrm{yr}$ of electricity for hydrogen production via electrolysis. The assumed electricity consumption in 2030 is $14.7 \mathrm{TWh} / \mathrm{yr}$ for PEVs and $0.7 \mathrm{TWh} / \mathrm{yr}$ for hydrogen production. The share of PEVs with uncontrolled loading is reduced from $70 \%$ in 2030 to $15 \%$ in 2050 . 


\section{Overhead lines $(\mathrm{OH})$}

Variant $\mathrm{OH}$ assumes a transmission grid expansion with overhead lines having a specific capacity of $3.2 \mathrm{GW}$ per line. For a $1,000 \mathrm{~km}$ transmission, specific costs per MW are about half of those for underground cables, whereas for a $250 \mathrm{~km}$ transmission these are only $25 \%$ lower due to the conversion station, which is similar in both cases.

\section{Underground cables $(x 2)$}

In the variant $x 2$ we assume double investment cost for expanding the transmission network compared to Base. Cost assumptions are derived from real costs for the HVDC interconnection between Spain and France, which includes the construction of a tunnel through the Pyrenees.

\section{Trans-European Power System (Trans)}

Trans considers power imports in Europe from concentrating solar power plants (CSP) in North Africa equal to about $15 \%$ of the European annual electricity consumption in 2050. The share of power generation from local energy sources is substantially lower: minus $148 \mathrm{GW}$ for wind power, minus $72 \mathrm{GW}$ for photovoltaics, and minus $23 \mathrm{GW}$ for other renewables in all regions considered. The installed CSP capacity in Africa is assumed to be around $70 \mathrm{GW}$ in 2050. REMix determines the optimal operation of the CSP plants and of the HVDC links between North Africa and Europe.

\section{Scenario variants with regard to EVs}

The following scenario variants are used to quantify impacts of flexible PEV charging and hydrogen production on the power system in Germany in 2030 and 2050: 
Uncontrolled loading $(\boldsymbol{U} \boldsymbol{L})$ : Charging of PEVs starts immediately after the last drive at maximum power.

Controlled loading $(\boldsymbol{C L})$ : All PEVs are charged during times of low electricity prices.

Vehicle to grid (V2G): Like $C L$ but PEVs can feed power back to the grid.

Hydrogen (H2): Electrolysers for onsite generation have double capacity compared to Base; thus, annual utilisation of electrolysers is approximately halved to around 2,000 full load hours per year.

Hydrogen plus $(\boldsymbol{H 2 +})$ : Like $H 2$ but with a storage capacity equal to the average hydrogen demand of one week instead of 12 hours.

No Electric Vehicles $(\boldsymbol{N E V})$ : Neither PEVs nor FCVs become a viable alternative to conventional vehicle concepts. Renewable power generation is reduced compared to Base to account for the lower power consumption.

\section{Results}

\subsection{Reduced residual peak demand and electricity losses}

The impacts of EV charging on the residual peak demand and losses in the German power system are shown for all scenarios in Figure 5. The residual peak demand relates to the need for thermal power generation (including cogeneration) during the $5 \%$ of hours with the highest load ${ }^{4}$. Residual peak demand represents total peak

4 We observed a high sensitivity of peak demand definition on calculated EV impacts when comparing different loading strategies. Comparing the maximum residual peak demand or the $95^{\text {th }}$ percentile changes the results significantly, even for similar model runs, due to the high variability of wind power and photovoltaics and the interdependencies between the regions. This effect can be moderated by averaging the results for the $5 \%$ of hours with the highest load. 
demand minus the feed-in of variable renewable power generation. System losses consist of transmission losses, pump losses, and power curtailments (renewable surpluses). The left side of the Figure shows the development in Base scenario from 2010 to 2050. The right side provides the same dispatch parameters for the scenario variants $O H, x 2$, and Trans in 2050. The results show that electricity losses increase from $1.1 \mathrm{TWh} / \mathrm{yr}$ in 2010 to $8.3 \mathrm{TWh} / \mathrm{yr}$ in 2050 along with RES expansion. The level of residual peak demand decreases from around 70 to $38 \mathrm{GW}$ because renewable power plants displace thermal generators. Pumped storage is the main source of losses in 2010, whereas in 2030 curtailment of renewable generation becomes relevant as well. Utilization of pumped storage plants reduces until 2050, but curtailments increase significantly. Especially controlled EV charging reduces the need for short-term electricity storage by pumped hydro. Assuming lower costs of overhead lines $(\mathrm{OH})$ increases the expansion of the transmission grid calculated by REMix. This effect reduces the residual peak demand slightly to $37 \mathrm{GW}$ and losses to 7.5 TWh/yr. Higher cost assumptions for transmission grid expansion ( $x 2)$ lead to the opposite effect, which is more pronounced. The Trans scenario results in both a lower peak demand of around $35 \mathrm{GW}$ and significantly lower losses in the power system. The reason behind is that solar thermal power plants can provide dispatchable power by using low-cost heat storage systems. 


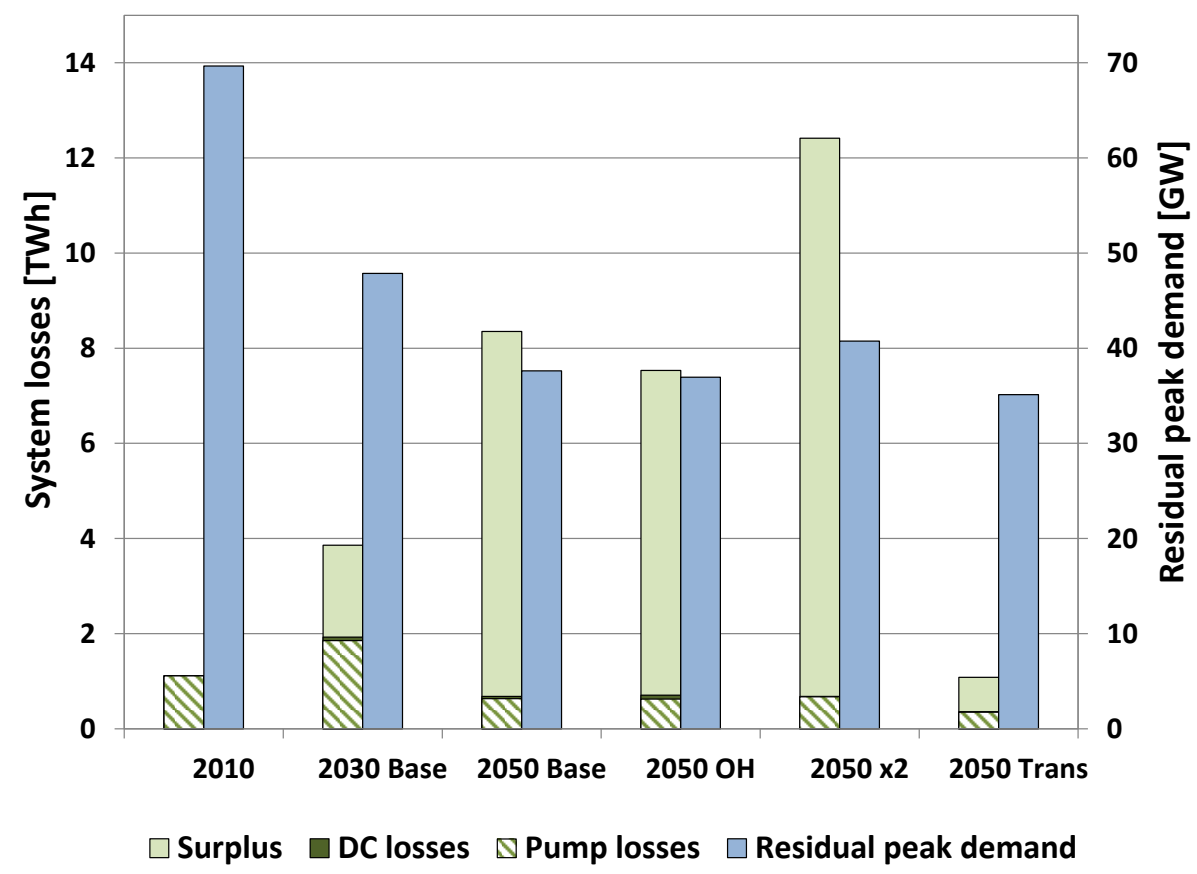

Figure 5: Annual system losses and residual peak demand in 2030 and 2050 in Germany compared to 2010 - results for all scenarios.

The impact of EVs, controlled charging strategies and different hydrogen station configurations on the above presented metrics are presented in Figure 6 for Base, $x 2$ and Trans. The systemic impact of smart charging strategies for PEVs is estimated as difference between the scenarios with controlled $(C L$ or $V 2 G)$ and with uncontrolled (UL) loading $(C L-U L, V 2 G-U L)$. The impact of larger electrolysers $(H 2)$ and in addition higher storage capacities $(\mathrm{H} 2+)$ is calculated by comparing the corresponding scenario variants with Base (H2-Base, H2+-Base) resp. $x 2$ and Trans. Finally, the systemic impact of EVs and the additional expansion of RES to cover their annual electricity demand is derived from differences between the scenarios Base resp. $x 2$ and $N E V$ (Base-NEV and $x 2-N E V$ ).

The resulting impact of EVs in 2030 is rather low because their assumed electricity demand is less than $3 \%$ of the total consumption. However, maximum electricity savings due to controlled loading can be up to $1.4 \mathrm{TWh} / \mathrm{yr}$, equal to $9.5 \%$ of the annual electricity consumption of PEVs. Savings in 2050 increase in Base up to 4.7 
TWh/yr corresponding to $9.6 \%$ of the PEV demand, the savings in $x 2$ will reach $12 \%$ and the savings in Trans will reach only $3.5 \%$ of the PEV demand due to the lower share of variable power generation from wind and photovoltaics. $C L$ resp. $V 2 G$ reduces the residual peak demand by around $1.2 \mathrm{GW}$ in 2030 and $4.5 \mathrm{GW}$ in 2050 for Base. The latter represents the power capacity of 2 resp. 8 large combined cycle gas power plants. Peak load reductions due to $C L / V 2 G$ are lower in $x 2(3.8 \mathrm{GW})$ and Trans $(3.5 \mathrm{GW})$, which is a result of different transfer capacities resp. generation mixes.

The results of $H 2$ and $H 2+$ reveal that increased electrolyser capacities have no systemic impact if the hydrogen storage capacities are not enlarged as well (H2Base). In the case of a doubled electrolyser capacity and an increased storage equal to one week of average hydrogen demand compared to 12 hours, the achievable reductions in system losses in 2050 would be $6 \mathrm{TWh} / \mathrm{yr}$ for Base (H2+-Base) and 8 $\mathrm{TWh} / \mathrm{yr}$ for $x 2(H 2+-x 2)$. System losses in Trans are much lower owing to generally lower surpluses. Residual peak load reductions compared to Base lie between 4 and 5 GW for all $\mathrm{H} 2+$-scenario variants for 2050 .

The impact of EV integration on surpluses is small but positive (Base-NEV) due to the additional renewable generation capacity required to meet their demand. Controlled loading may counterbalance this effect to a large extent; however, a reduced expansion of transfer capacities still results in significantly higher surpluses $(x 2-N E V)$. PEV integration increases the residual peak demand in 2030 because of largely uncontrolled loading. The impact on the residual peak demand is different in 2050, when most PEVs are assumed to be able to shift demand from peak to off-peak periods. 
Integrating EVs with 100\% uncontrolled PEV loading would increase the residual peak load of the system by around $1 \mathrm{GW}$ in 2030 and $3 \mathrm{GW}$ in 2050 as the difference between the $U L$ variant of Base and NEV. Additional system losses due to EV integration would be approximately 4.3 to $7.3 \mathrm{TWh} / \mathrm{yr}$ in 2050 , depending on transfer capacities between regions. These numbers take into account concurrent effects associated with the flexible hydrogen production.
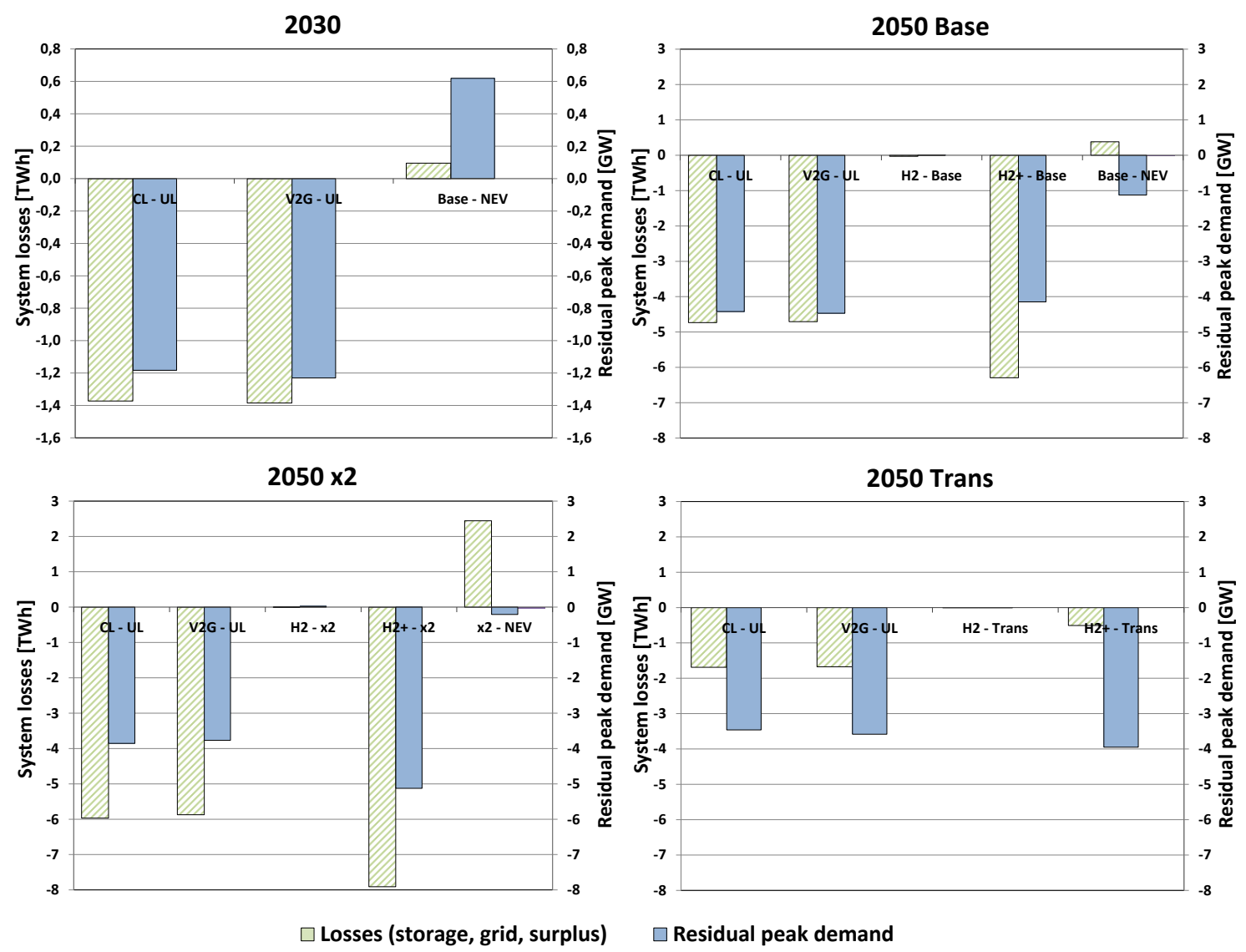

Figure 6: Impact of PEVs and hydrogen production on losses and residual peak demand in Germany in 2030/2050 - differences between variants of Base, $x 2$ and Trans scenarios.

\subsection{Cost efficient transmission system expansion}

The REMix results for transmission system expansion are presented in Figure $\mathbf{7}$ for Germany and summarised for all regions considered (incl. Germany). Sensitivities of different EV variants in 2050 are shown in Figure 8 for all regions. Figure 7 shows 
on the left side results for Germany in the scenario Base compared to 2010. The total length of the HVDC lines between Germany and its neighbouring countries calculated based on the distances between the geometric centres of the regions grows up to 14 Mio. MW $\cdot \mathrm{km}$ (MW transfer capacity multiplied by km cable length). The length of HVDC lines between all regions considered increases from 1 Mio. MW $\cdot \mathrm{km}$ in 2010 , to 14 Mio. MW $\cdot \mathrm{km}$ in 2030 and to $56 \mathrm{Mio}$. MW $\cdot \mathrm{km}$ in 2050. In the scenario variant $O H$, the assumed lower grid investment costs lead to a 14\% higher expansion in 2050 compared to Base. Grid expansion is $30 \%$ lower if double investment costs are assumed (x2), more than $200 \%$ higher in the case of solar electricity imports in Trans and decreases by 25\% without EVs and less renewable electricity generation (NEV). Most grid capacity expansion in Trans is directly associated with the import of solar power from North Africa to consumption centres in central Europe via HVDC lines, which is taken into account in Figure 7 and Figure 8.
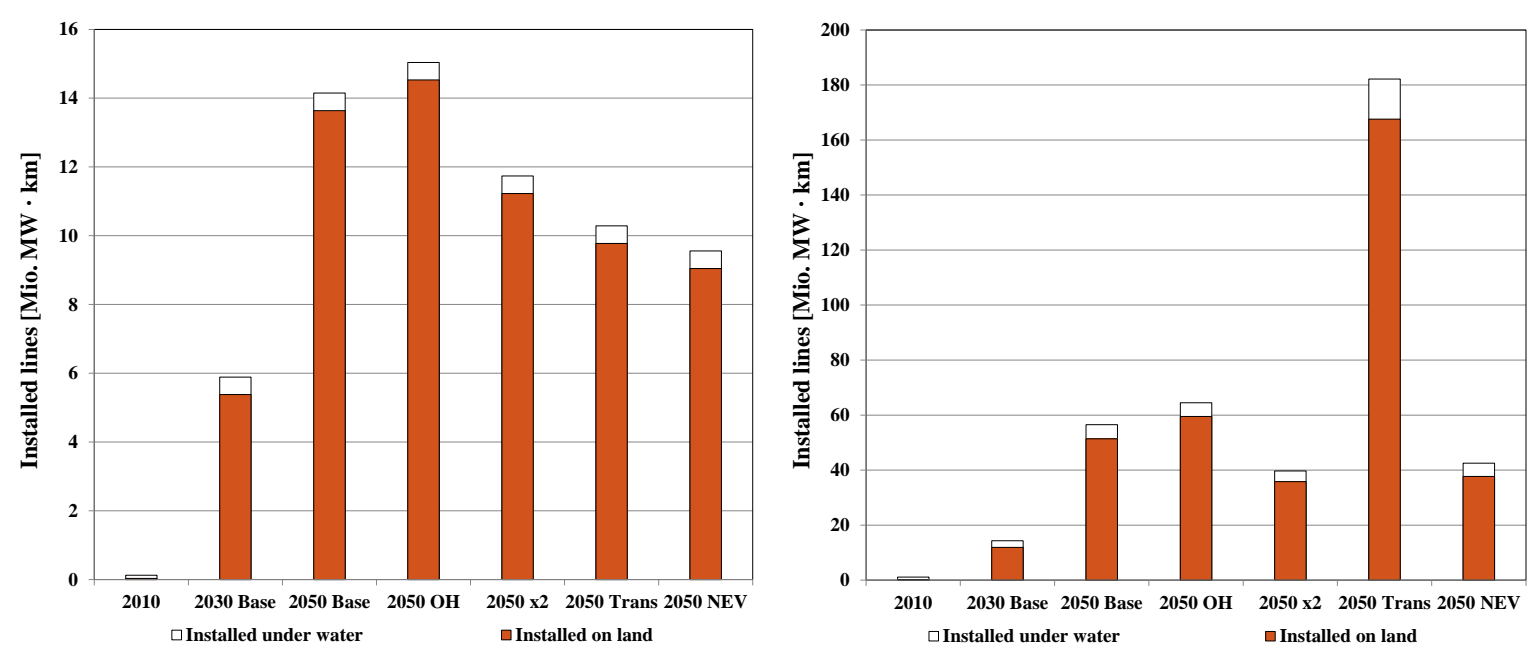

Figure 7: HVDC transmission expansion in all regions (right) and between Germany and its neighbouring countries (left) - results for all scenarios.

The sensitivity analysis for Base shows that for 2050, when around $20 \%$ of total electricity demand is owing to EVs, implementing controlled charging could lead to 
a reduction in grid expansion of $9.2 \%$ for unidirectional $(C L-U L)$ and of $9.4 \%$ for bidirectional loading $(V 2 G-U L)$. Doubling the capacity of electrolysers $(H 2)$ does not significantly increase savings, unless the hydrogen storage is augmented as well $(H 2+)$. Grid expansion is reduced by $29 \%$ compared to Base in the $H 2+$ scenario. Savings are slightly larger than the reductions of around $27 \%$ if no EVs are assumed $(N E V)$. Thus, a flexible hydrogen production infrastructure with weekly storages could compensate for the transmission grid expansion required for EVs.

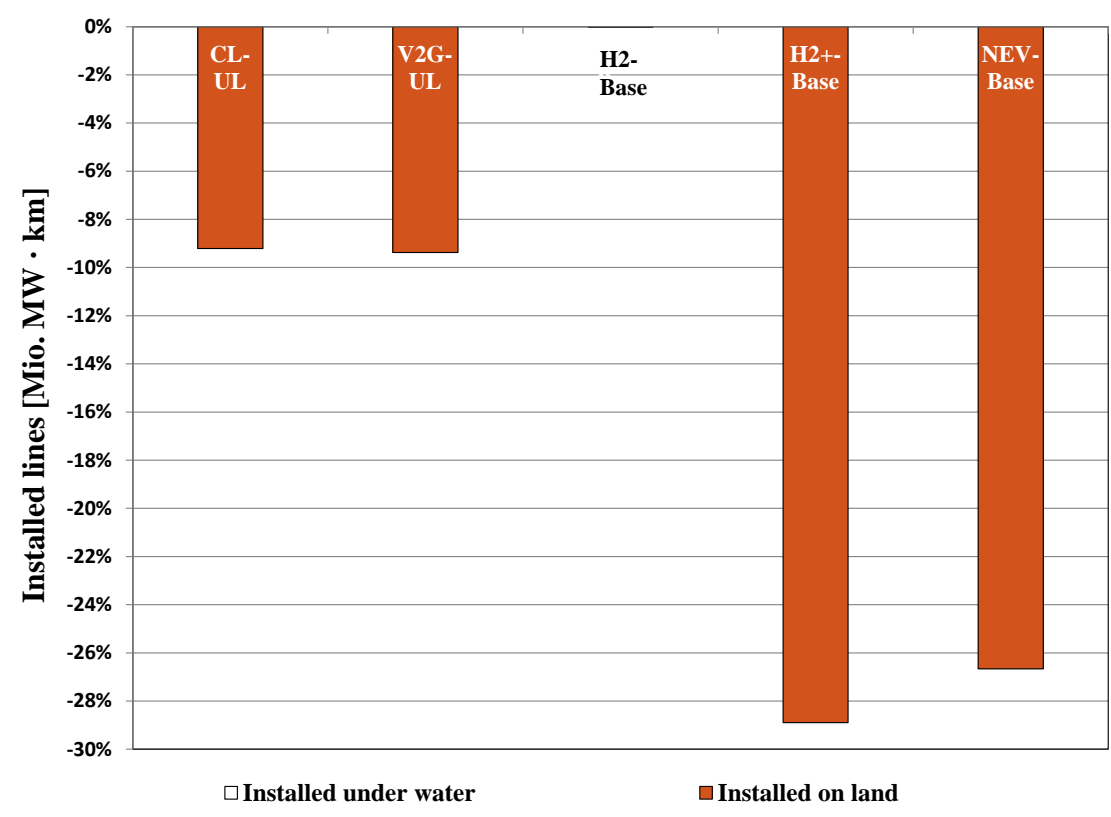

Figure 8: Impact of PEVs and hydrogen production on HVDC transmission grid expansion in all regions in $\mathbf{2 0 5 0}$ - differences between variants of Base scenario. 


\subsection{Reduced system costs due to controlled charging}

This section presents calculated impacts of controlled PEV charging and flexible hydrogen supply systems on operation and expansion costs in the power sector. Expansion costs are defined as the annuity of investment in grid expansion and new gas turbines as back-up capacity, which are endogenously calculated. The need for additional gas turbines is derived from the calculated residual peak load, assuming that installation is higher in case of an increase and lower in case of a decrease. Main components of the operational costs are fixed operation and maintenance costs for all generators and lines, costs of fuels and $\mathrm{CO}_{2}$ certificates, costs of $\mathrm{EV}$ battery degradation due to V2G. In addition, costs related to not supplied energy are considered by an assumed value of lost load of 2,000 EUR/MWh.

Figure 9 shows that annual savings could be on the order of several hundreds of MEUR per year for the German power system. However, controlled loading could also provide ancillary services that are not considered in the analysis. The most important source of savings in our modelling approach is operating costs followed by generation expansion. Possible savings in 2030 for $C L$ and for $V 2 G$ will reach 254 MEUR and 288 MEUR compared to $U L$. In 2050 these amount to 858 MEUR for $C L$ and 867 MEUR for $V 2 G$. Compared to Base, a flexible hydrogen production with weekly storage $(\mathrm{H} 2+)$ reduces system costs by 1,021 MEUR. Higher transmission line costs $(x 2)$, which result in lower transmission grid expansion, increase potential savings to 1,012 MEUR for $C L$, approximately 1,020 MEUR for $V 2 G$ and to 1,255 MEUR for $H 2+$. Savings in Trans are significantly lower, accounting for 476 MEUR for $C L, 481$ MEUR for $V 2 G$ and 426 MEUR for $H 2+$. Neither bidirectional loading nor larger electrolysers without larger gas storage result in relevant benefits concerning the system costs. 

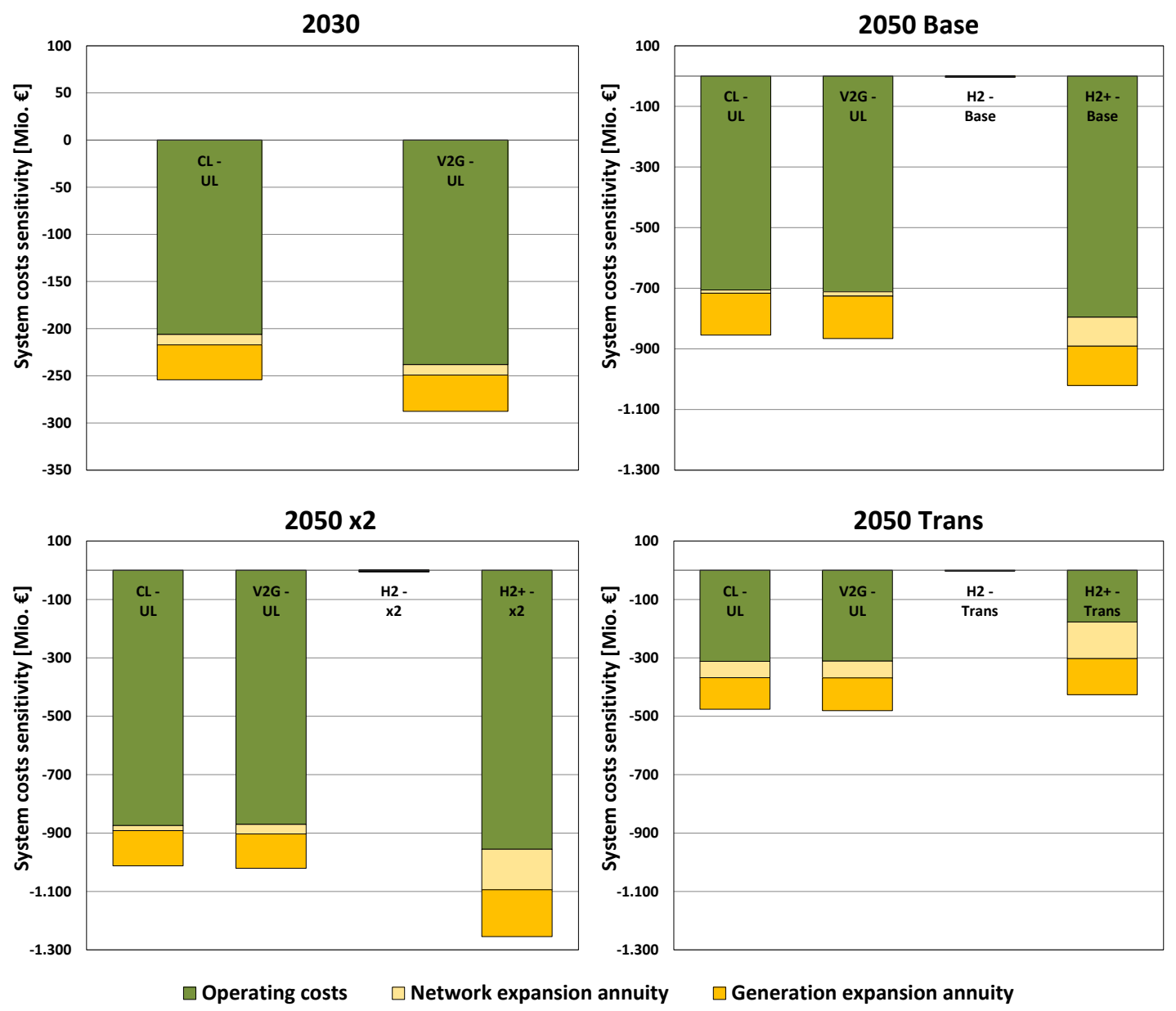

Figure 9: Impact of PEVs and hydrogen production on annual power system costs in Germany 2030/2050 - differences between variants of Base, $x 2$ and Trans scenarios.

\section{Discussion and Conclusions}

This work assumes the successful development of BEVs and EREVs, accounting for two thirds of the car fleet, as well as of FCVs, which is in line with the political targets of the German energy transition regarding efficiency, renewable energies and 80\% GHG emission reduction by 2050 (related to 1990). This ambitious development path requires substantial government support, acceptance from all relevant actors and significant technological progress, e.g., of lithium batteries.

Electric vehicles lead to increasing power system requirements due to their additional and variable demand and the added renewable electricity generation needed to power them. The assumed additional demand of PEVs and FCVs will reach around $20 \%$ of 
total electricity demand in Germany in 2050. Uncontrolled loading would increase the residual peak demand in the power system. Comparing Base and $N E V$ scenarios confirms that electric vehicles will increase the residual peak demand in 2030 but can decrease it in 2050 if battery charging is controlled to a large extent. Controlled loading can avoid 3.5 to $4.5 \mathrm{GW}$ of the residual peak load and can lead to systemic efficiency gains of about $10 \%$ of the electricity consumption of all PEV in Germany compared to uncontrolled loading. Compared to the German power system of today, these values represent around $5 \%$ of the total peak load and $1 \%$ of the total electricity demand, respectively. Therefore, controlled loading strategies may become relevant for the energy markets; however, it is obvious that even an optimal integration of PEVs cannot be the only solution for balancing loads in energy systems with high shares of RES.

In addition, assuming a flexible hydrogen production infrastructure with weekly storage at fuelling stations could completely offset transmission network expansion requirements due to $\mathrm{EV}$ integration. However, the results clearly show that increasing the electrolyser's capacity to achieve a lower utilization would only increase power system flexibility by enlarging as well the hydrogen storage. As large high pressure hydrogen storages at fuelling stations would probably be confronted with low public acceptance, this result may indicate that a more centralized hydrogen supply structure, e.g. by using large underground caverns, could be more convenient for the storage of pressurized hydrogen (see also results of [44] regarding power system effects of hydrogen production).

The estimated benefit of controlled loading strategies for the power system is mainly due to reduced operating costs and lower investment needs regarding electricity production and transmission. Controlled charging of PEVs could reduce system costs 
by approximately 250 MEUR by 2030 (around 50 EUR per PEV and year) and by around 850 MEUR by 2050 (around 30 EUR per PEV and year). In case of a flexible hydrogen production with weekly storage capacities annual savings would account for around 1,000 MEUR in 2050. These estimations do not take into account possible additional investment needs in distribution grids and ICT systems and possible benefits from ancillary services. In addition, we did not consider further economic benefits in the scenarios due to a possible 'second life' of PEV batteries if they are repurposed after the automotive end of life as stationary storage systems. These aspects remain subject for further research.

The results of the EV scenario variants for Germany reveal also impacts on the European neighbouring countries. The residual peak demand is reduced in Base by controlled PEV charging by $11.4 \mathrm{GW}$ in all regions and losses are reduced by 5.7 TWh per year compared to uncontrolled charging. The transmission grid expansion in Trans differs significantly in Germany compared to all countries regarding additional transfer capacities and lines for solar power import. Our approach of a HVDC super grid leads to high investments on the European scale whereas the sum of transfer capacities between German regions and between Germany and its neighbouring countries are not increased in the Trans scenario compared to Base.

It is not an easy task to compare our results with those of other studies as modelling approaches and assumptions are usually different. However, we see that all studies have generally similar conclusions regarding the positive effects of EV integration on power systems. Schill and Gerbaulet [27] calculated comparable results for the reduction of RES curtailment due to controlled charging in scenarios for 2030 that also include the additional installation of RES for PEV supply. Their calculations resulted in an around $0.8 \mathrm{TWh} / \mathrm{yr}$ curtailment reduction assuming a total power 
demand of PEV of around $9 \mathrm{TWh} / \mathrm{yr}$ compared to a $1.4 \mathrm{TWh} / \mathrm{yr}$ curtailment reduction at around $15 \mathrm{TWh} / \mathrm{yr} \mathrm{PEV}$ power demand in our analysis. Some similar conclusions can also be found in Verzijlbergh et al. [28], e.g., regarding reduced pumped hydro utilization and reduced need for transmission capacity due to controlled EV charging. Forrest et al. [18] also found controlled EV charging reduced the need for short-term electricity storage; however, they demonstrated a much higher system benefit of bidirectional V2G compared to controlled charging. This benefit is primarily the result of neglecting costs owing to additional battery degradation, whereas in our analysis, the cost assumptions result in a notably low utilization of V2G.

The scenarios represent a long-term transition of the mobility sector from fossil fuels to renewable electricity, which results in a strong reduction of greenhouse gas emissions. Controlled charging of plug-in electric vehicles and flexible hydrogen generation both appear to be important factors in this transition that enable an efficient integration of the renewable electricity generation required to power electric vehicles in terms of residual peak demand, losses and transmission network expansion.

\section{Acknowledgement}

The authors would like to thank the German Federal Ministry for Economic Affairs and Energy (BMWi) for funding the underlying research project, 'Prospects for electric/hybrid vehicles in a power supply system dominated by decentralized, renewable energy sources', FKZ 0328005. 


\section{References}

[1] German Federal Government. Energiekonzept für eine umweltschonende, zuverlässige und bezahlbare Energieversorgung. Berlin, 2010 (in German).

[2] Luca de Tena D. Large scale renewable power integration with electric vehicles. PhD thesis, University of Stuttgart and DLR, 2014.

[3] Pregger T, Luca de Tena D, O’Sullivan M, Roloff N, Schmid S, Propfe B, Hülsebusch D, Wille-Haussmann B, Schwunk S, Wittwer C, Pollok T, Krahl S, Moormann A. Perspektiven von Elektro-/Hybridfahrzeugen in einem Versorgungssystem mit hohem Anteil dezentraler und erneuerbarer Energiequellen (Prospects for electric/ hybrid vehicles in a power supply system dominated by decentralized, renewable energy sources). Final report DLR/FhG ISE/IfHT, project funded by the (former) Federal Ministry for Economics and Technology (BMWi) (in German), 2012.

[4] Baños R. Optimization methods applied to renewable and sustainable energy: A review. Renewable and Sustainable Energy Reviews, 15 (4), p. 1753-1766, 2011. [5] Foley AM, Ó Gallachóir BP, Hur J, Baldick R, McKeogh EJ. A strategic review of electricity systems models. Energy, 35 (12), p. 4522-4530, 2010.

[6] Galus MD, Vayá MG, Krause T and Andersson G. The role of electric vehicles in smart grids. Wiley Interdisciplinary Reviews: Energy and Environment, Volume 2, Issue 4, p. 384-400, 2013.

[7] Suganya S, Charles Raja S, Srinivasan D, Venkatesh P. Smart utilization of renewable energy sources in a microgrid system integrated with plug-in hybrid electric vehicles. Int J Energy Res., Article in press, DOI: 10.1002/er.3921, 2017.

[8] Pieltain L, Gómez T, Cossent R, Mateo C, Frías P. Assessment of the Impact of Plug-in Electric Vehicles on Distribution Networks. IEEE Transactions on Power Systems, 26 (1), p. 206-213, 2011.

[9] Suganya S, Charles Raja S, Venkatesh P. Smart management of distinct plugin hybrid electric vehicle charging stations considering mobility pattern and site characteristics. Int J Energy Res, 41 (14), p. 2268-2281, 2017. 
[10] Dallmer-Zerbe K, Stillahn T, Erge T, Wille-Haussmann B, Wittwer C. Analysis of the Exploitation of EV Fast Charging to Prevent Extensive Grid Investments in Suburban Areas. Energy Technology, Vol. 2, Issue 1, p. 54-63, 2014. [11] Dallinger D, Link J and Büttner M. Smart Grid Agent: Plug-in Electric Vehicle. IEEE Transactions on Sustainable Energy, Vol. 5, No. 3, July 2014.

[12] Kempton W and Tomic J. Vehicle-to-grid power fundamentals: Calculating capacity and net revenue. Journal of Power Sources, 144 (1), p. 268-279, 2005. [13] Kempton W and Tomic J. Vehicle-to-grid power implementation: From stabilizing the grid to supporting large-scale renewable energy. Journal of Power Sources, 144 (1), p. 280-294, 2005.

[14] Pavić I, Capuder T, Kuzle I. Value of flexible electric vehicles in providing spinning reserve services. Applied Energy, 157, p. 60-74, Nov. 2015.

[15] Schill WP, Niemeyer M, Zerrahn A, Diekmann J. Bereitstellung von Regelleistung durch Elektrofahrzeuge in Deutschland: Modellrechnungen für das Jahr 2035. Zeitschrift für Energiewirtschaft, 2016 (in German).

[16] Kintner-Meyer $M$ et al. Impact assessment of plug-in hybrid vehicles on the U.S. Power Grid. The 25th World Battery, Hybrid and Fuel Cell Electric Vehicle Symposium \& Exhibition, EVS-25, Shenzhen, China, Nov. 5-9, 2010.

[17] McCarthy RW. Assessing Vehicle Electricity Demand Impacts on California Electricity Supply, PhD thesis, Institute of Transportation Studies. University of California, Davis, 2009.

[18] Forrest KE, Tarroja B, Zhang L, Shaffer B, Samuelsen S. Charging a renewable future: The impact of electric vehicle charging intelligence on energy storage requirements to meet renewable portfolio standards. Journal of Power Sources, 336, p. 63-74, 2016.

[19] Tarroja B, Zhang L, Wifvat V, Shaffer B. Samuelsen S. Assessing the stationary energy storage equivalency of vehicle-to-grid charging battery electric vehicles. Energy, 106, p. 673-690, 2016.

[20] Zhang L, Jabbari F, Brown T, Samuelsen S. Coordinating plug-in electric vehicle charging with electric grid: valley filling and target load following. Journal of Power Sources, 267, p. 584-597, 2014. 
[21] Lund $\mathrm{H}$ and Kempton W. Integration of renewable energy into the transport and electricity sectors through V2G. Energy Policy, 36, Issue 9, p. 3578-3587, 2008.

[22] Fernandes C, Frías P, Latorre JM. Impact of vehicle-to-grid on power system operation costs: The Spanish case study. Applied Energy, 96, p. 194-202, 2012.

[23] Teng F, Aunedi M, Strbac G. Benefits of flexibility from smart electrified transportation and heating in the future UK electricity system. Applied Energy, 167, p. 420-431, 2016.

[24] Dallinger D, Schubert G, Wietschel M. Integration of intermittent renewable power supply using grid-connected vehicles - a 2030 case study for California and Germany. Applied Energy, 104, p. 666-682, 2013.

[25] Metz M and Doetsch C. Electric vehicles as flexible loads - A simulation approach using empirical mobility data. Energy, 48, (1), p. 369-374, 2012.

[26] Zumkeller D et al. Regional panels against the background of the German Mobility Panel - an integrated approach. Paper presented at ISCTSC, 2008.

[27] Schill WP and Gerbaulet C. Power system impacts of electric vehicles in Germany: Charging with coal or renewables? Applied Energy, 156, p. 185-196, 2015.

[28] Verzijlbergh R, Brancucci Martínez-Anido C, Lukszo Z, de Vries L. Does controlled electric vehicle charging substitute cross-border transmission capacity? Applied Energy, 120, p. 169-180, 2014.

[29] ENTSO-E, Scenario Outlook \& Adequacy Forecast; 2012-2030, https://www.entsoe.eu/publications/, 2012.

[30] Scholz Y. Renewable energy based electricity supply at low costs: development of the REMix model and application for Europe. $\mathrm{PhD}$ thesis, Universität Stuttgart, http://dx.doi.org/10.18419/opus-2015, 2012.

[31] Gils HC, Scholz Y, Pregger T, Luca de Tena D, Heide D. Integrated modelling of variable renewable energy-based power supply in Europe. Energy, 123, 15 March 2017, p. 173-188.

[32] Propfe B and Luca de Tena D. Perspectives of electric vehicles: customer suitability and renewable energy integration. The 25th World Battery, Hybrid and Fuel Cell Electric Vehicle Symposium \& Exhibition, Shenzhen, China, 2010. 
[33] infas and DIW. Mobilität in Deutschland (MiD). Federal Ministry of Transport, Building and Urban Development, 2008 (in German).

[34] USCAR - United States Council for Automotive Research LLC. EV Batteries Development RFPI Final. U.S. Advanced Battery Consortium, Dec. 2009. http://www.uscar.org/commands/files_download.php?files_id=217

[35] André M. The ARTEMIS European driving cycles for measuring car pollutant emissions. Science of the Total Environment, Vol. 334-335, p. 73-84, 2004. [36] Nitsch J et al. Leitstudie 2010 - Long term scenarios and strategies for the deployment of renewable energies in Germany under the consideration of European and global developments. Project report, Federal Ministry for the Environment (BMU) (in German), 2011.

[37] Mock P, Hülsebusch D, Ungethüm J, Schmid S. Electric vehicles - A model based assessment of future market prospects and environmental impacts. World Electric Vehicle Journal, Vol. 3, 2009.

[38] Pregger T, Luca de Tena D, Schmid S, Wille-Haussmann B, Pollok T, Sowa T. Optimierte Integration der Elektromobilität in das Stromversorgungssystem bei hohen Anteilen erneuerbarer Energien. Zeitschrift für Energiewirtschaft, March 2013 (in German).

[39] Link $\mathbf{J}$ et al. Optimisation algorithms for the charge dispatch of plug-in vehicles based on variable tariffs. Working paper Sustainability and Innovation, $3 / 2010$.

[40] Pregger T, Nitsch J, Naegler T. Long-term scenarios and strategies for the deployment of renewable energies in Germany. Energy Policy, Vol. 59, p. 350-360, 2013.

[41] Trieb F et al. Trans-Mediterranean interconnection for concentrating solar power. Project report, Federal Ministry for the Environment (BMU), http://www.dlr.de/tt/desktopdefault.aspx/tabid-2885/4422_read-6588/, 2006 (in German).

[42] ENTSO-E, European Network of Transmission System Operators: Ten-Year Network Development Plan. https://www.entsoe.eu. 
[43] Eurostat. Goods transport by road. http://ec.europa.eu/eurostat/, download 2012.

[44] Michalski J et al. Hydrogen generation by electrolysis and storage in salt caverns: Potentials, economics and systems aspects with regard to the German energy transition. International Journal of Hydrogen Energy, 42, p. 13427-13443, 2017. 